\title{
Effect of video learning multimedia toward health belief model of self breast examination
}

\section{Pengaruh video learning multimedia terhadap health belief model perilaku periksa payudara sendiri}

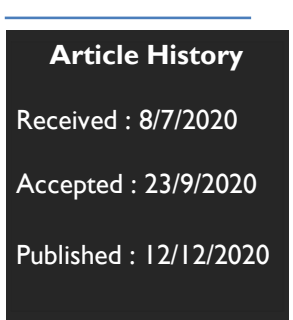

\author{
Fatmah Afrianty Gobel ${ }^{*}$, Nurfitriani², Samsualam ${ }^{3}$ \\ Afiliasi \\ 1,2,3 Program Studi Magister Kesehatan, Universitas Muslim Indonesia \\ Korespondensi \\ Email : ${ }^{\text {fatmahafrianty.gobel@umi.ac.id }}$
}

\begin{abstract}
Breast cancer is the most commonly diagnosed cancer and the second leading cause of death from cancer for women. The prevalence of cancer in Indonesia is 1.4 per 1000 inhabitants or about 330,000 people. VLM (Video Learning Multimedia) is a learning tool or medium using video or mobile display, using a combination of text, graphics, sound, video and animation. Aim of study was measure effect of VLM toward self breast examination behavior. This type of research is quantitative research with a population of 135 . As for the number of samples in this study as many as 60 respondents, which are divided into two groups namely, intervention group and control group. We used paired sample test with $95 \%$ confidence level, obtained $p$-value $=0.001$, meaning there was a difference in attitude before and after being educated on breast check behavior (SADARI) in the control group. Factors that facilitate the change in a person's behavior, consisting of knowledge, attitudes, and cultural values. It is expected that it will be useful for mothers in Buakana Village rappocini sub-district and society especially women who are more at high risk of breast cancer to not only study but perform breast examination themselves (SADARI) as an early detection of breast cancer.
\end{abstract}

Keywords: health belief model ( $\mathrm{hbm})$; multimedia video learning; self breast examination.

\begin{abstract}
Abstrak
Kanker payudara merupakan kanker yang paling sering didiagnosis dan penyebab kematian utama kedua akibat kanker bagi wanita. Prevalensi kanker di Indonesia adalah I,4 per 1000 penduduk atau sekitar 330.000 orang. VLM (Video Learning Multimedia) adalah sebuah alat atau media pembelajaran menggunakan gabungan dari teks, grafik, suara, video dan animasi. Tujuan penelitian untuk melihat pengaruh VLM terhadap perilaku periksa payudara sendiri (SADARI). Jenis penelitian ini adalah penelitian kuantitatif dengan jumlah populasi sebanyak 135. Adapun jumlah sampel pada penelitian ini sebanyak 60 responden, yang terbagi menjadi dua kelompok yakni, kelompok intervensi dan kelompok kontrol. Uji statistik dengan menggunakan uji Paired Sampel Test dengan tingkat kepercayaan 95\%, diperoleh nilai $p$-value $=0,00 \mathrm{I}$, artinya terdapat perbedaan sikap sebelum dan sesudah di berikan edukasi terhadap perilaku SADARI pada kelompok kontrol. Faktor yang mempermudah terjadinya perubahan perilaku seseorang, yang terdiri dari pengetahuan, sikap, dan nilai budaya. Diharapkan akan berguna bagi ibu-ibu di Kelurahan Buakana Kecamatan Rappocini dan masyarakat khususnya perempuan yang lebih berisiko tinggi menderita kanker payudara agar tidak hanya mempelajari tetapi melakukan SADARI sebagai deteksi dini kanker payudara.
\end{abstract}

Kata Kunci: health belief model $(\mathrm{hbm})$; video learning multimedia (vlm); pemeriksaan payudara sendiri (sadari) 


\section{Pendahuluan}

Promosi kesehatan merupakan upaya yang bersifat promotif (peningkatan), sebagai perpaduan dari upaya preventif (pencegahan), kuratif (pengobatan), dan rehabilitatif (pemulihan) dalam rangkaian upaya kesehatan yang komprehensif (Kholiq, 20/2). Berdasarkan hasil data WHO World Health Organization (2016) menyebutkan kanker payudara adalah kanker paling umum terjadi pada wanita baik di negara maju dan berkembang. Diperkirakan bahwa di seluruh dunia lebih dari 508.000 wanita meninggal pada tahun 2015 karena kanker payudara. Data dari GLOBOCAN (IARC) tahun 2017 dalam Pusdatin Kemenkes RI Stop Kanker (2017), kanker payudara di dunia mempunyai persentase kasus baru sebesar 43,3\% dan persentase kematian akibat kanker payudara sebesar 12,9\%.

VLM (Video Learning Multimedia) adalah sebuah alat atau media pembelajaran menggunakan video atau tampilan bergerak, media ini merupakan sebuah alat pembelajaran modern dikalangan masyarakat. Multimedia adalah penyampaian informasi menggunakan gabungan dari teks, grafik, suara, video dan animasi. Pembelajaran dengan menggunakan teknologi audiovisual akan meningkatkan kemampuan belajar sebesar $50 \%$, daripada tanpa menggunakan media (Munir, 2013).

Penelitian ini bertujuan menganalisis pengaruh video learning multimedia terhadap perilaku pemeriksaan payudara sendiri.

\section{Metode}

Jenis penelitian ini adalah penelitian kuantitatif dengan jumlah populasi sebanyak 135. Adapun jumlah sampel pada penelitian ini sebanyak 60 responden, yang terbagi menjadi dua kelompok yakni, kelompok intervensi dan kelompok kontrol. Setelah dilakukan uji statistik dengan menggunakan uji Paired Sampel Test dengan tingkat kepercayaan 95\%, diperoleh nilai $\mathrm{p}$-value= $0,00 \mathrm{I}$, artinya terdapat perbedaan sikap sebelum dan sesudah di berikan edukasi terhadap perilaku periksa payudara sendiri (SADARI) pada kelompok kontrol. Faktor yang mempermudah terjadinya perubahan perilaku seseorang, yang terdiri dari pengetahuan, sikap, dan nilai budaya.

\section{Hasil}

Data dari 30 responden kelompok intervensi (grafik I) diketahui bahwa responden yang usianya 26 tahun sebanyak 7 orang $(23,3 \%)$, yang usianya 27 tahun 
sebanyak 16 orang $(53,3 \%)$, usianya 30 $(16,7 \%)$, yang usianya $>35$ tahun sebanyak 2 orang (6,7\%). Selanjutnya, sebaran responden kelompok Kontrol berdasarkan usia diperoleh data bahwa dari 30 responden diketahui yang usianya 26 tahun tahun sebanyak 5 orang, yang usianya 27 tahun sebanyak II orang (36,7\%), usianya 30 tahun sebanyak 2 orang $(6,7 \%)$, yang usianya $>35$ tahun sebanyak I orang $(3,3 \%)$.

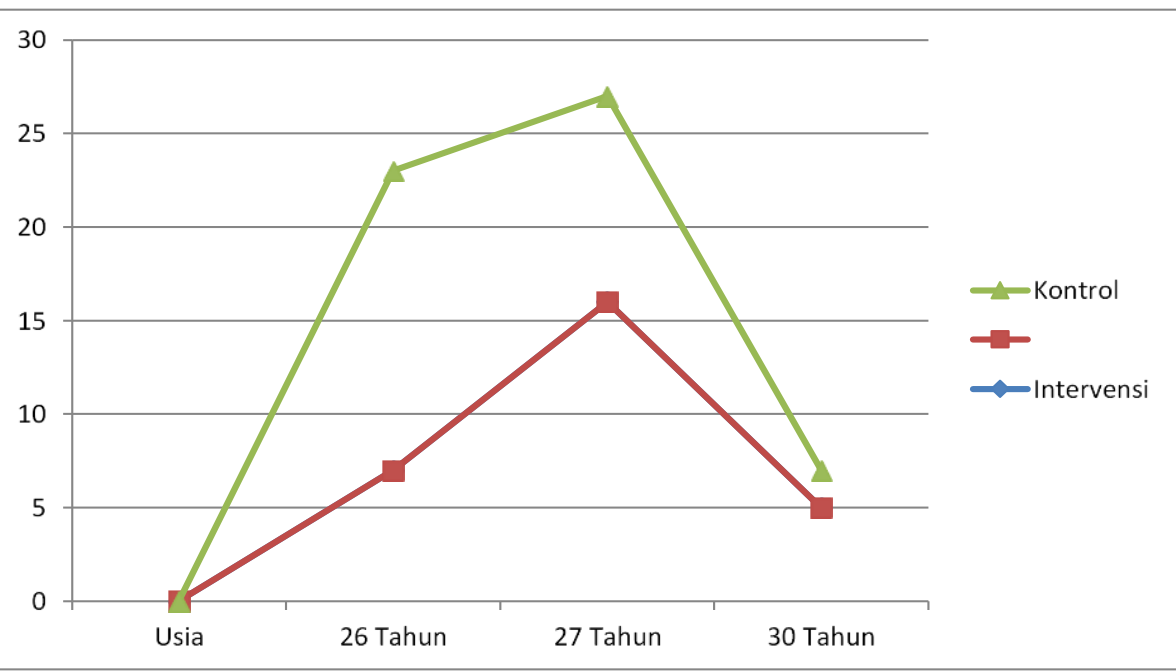

Grafik I. Distribusi Usia Responden(Sumber : Data Primer)

Berdasarkan hasil pretes terhadap variabel (Grafik 2) diketahui bahwa Variabel pengetahuan dengan kategori kurang sebanyak 19 orang $(63,3 \%)$, dan kategori baik sebanyak II (36,7\%). Kelompok kontrol diketahui variabel pengetahuan dengan kategori kurang sebanyak 18 orang (60,0\%), dan kategori baik sebanyak 12 $(40,0 \%)$. Selanjutnya, kelompok intervensi kontrol yang tidak melakukan sadari sebanyak 13 orang $(43,3)$. diketahui variabel sikap dengan kategori kurang sebanyak 18 orang $(60,0 \%)$, dan kategori baik sebanyak 12 orang $(40,0 \%)$. Kelompok kontrol diketahui variabel sikap dengan kategori kurang sebanyak 20 orang $(66,7 \%)$ dan kategori baik sebanyak 10 (33,3\%). Dari perilaku responden yang tidak melakukan sadari pada kelompok intervensi sebanyak 4 orang (13,3\%), dan kelompok 


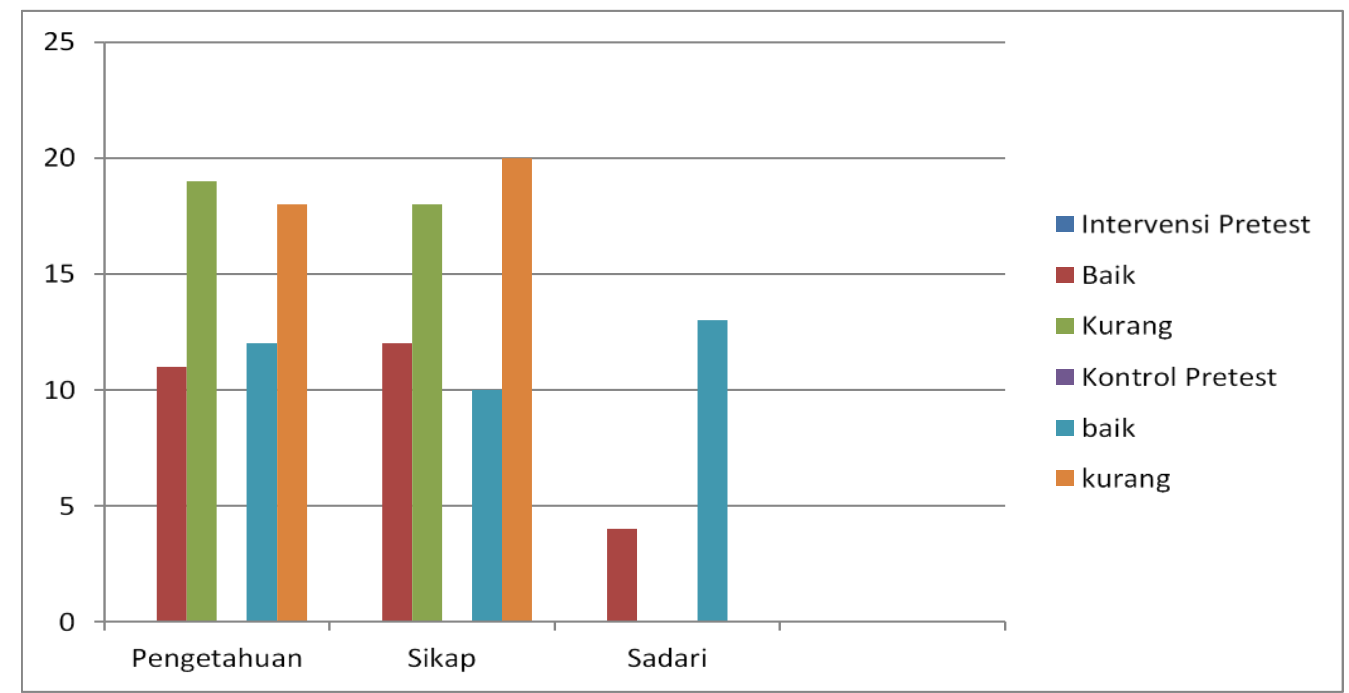

Grafik 2. Distribusi Hasil Pretest Pengetahuan, Sikap, dan Tindakan SADARI (sumber : Data primer)

Berdasarkan hasil posttes terhadap variabel (Grafik 3) Variabel pengetahuan dengan kategori kurang sebanyak 19 orang $(63,3 \%)$, dan kategori baik sebanyak II (36,7\%). Kelompok kontrol diketahui variabel pengetahuan dengan kategori kurang sebanyak 18 orang $(60,0 \%)$, dan kategori baik sebanyak 12 (40,0\%). Selanjutnya, kelompok intervensi diketahui variabel sikap (13,3\%), dan kelompok kontrol yang tidak melakukan sadari sebanyak 13 orang $(43,3)$ dengan kategori kurang sebanyak 18 orang $(60,0 \%)$, dan kategori baik sebanyak 12 orang (40,0\%). Kelompok kontrol diketahui variabel sikap dengan kategori kurang sebanyak 20 orang $(66,7 \%)$ dan kategori baik sebanyak 10 (33,3\%). Dari perilaku responden yang tidak melakukan sadari pada kelompok intervensi sebanyak 4 orang 


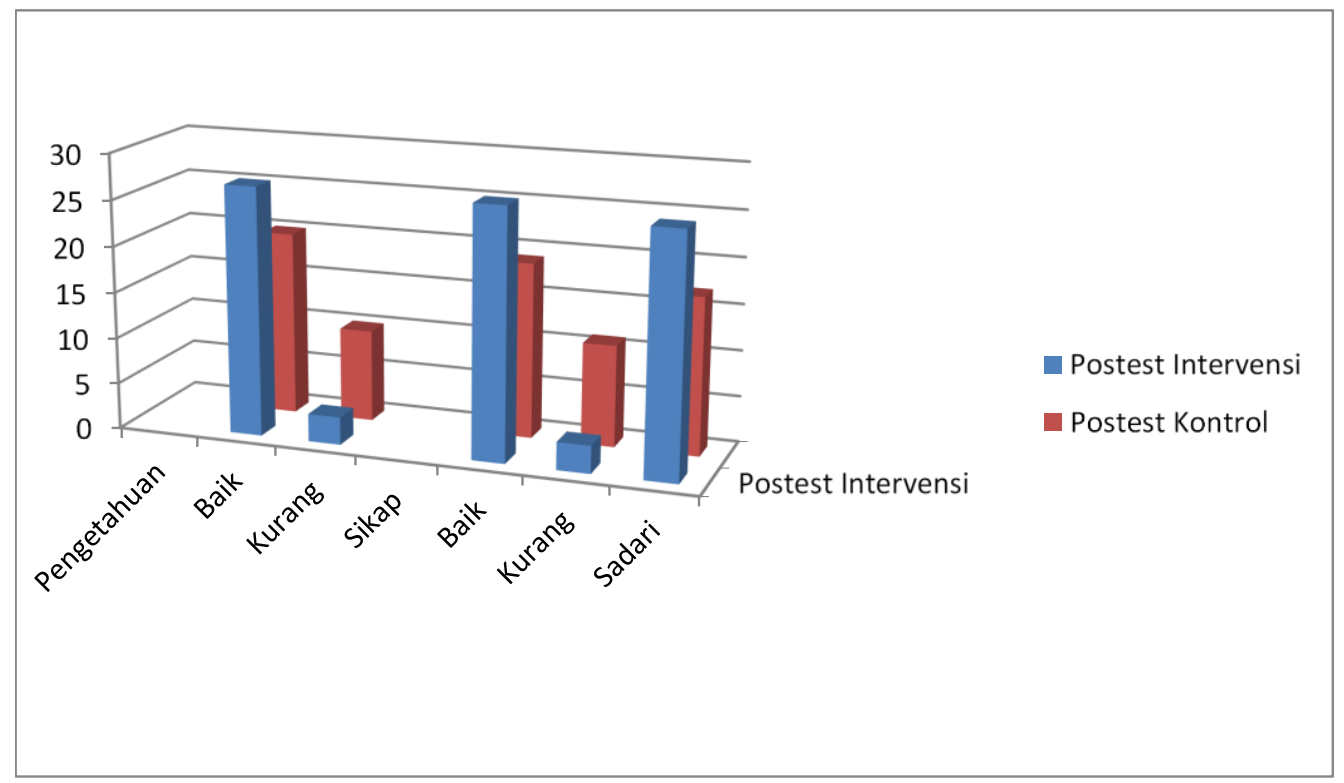

Grafik 3. Distribusi Hasil Posttest Pengetahuan, Sikap, dan Tindakan SADARI (Sumber : Data Primer)

\section{Pembahasan}

VLM (video learning multimedia) terhadap pengetahuan SADARI

Terdapat perbedaan pengetahuan sebelum dan sesudah di berikan edukasi terhadap pemeriksaan payudara sendiri (SADARI) pada kelompok perlakuan dan kelompok kontrol. Penelitian ini menunjukkan bahwa adanya peningkatan secara signifikan sebelum dan setelah diberikan promosi kesehatan.

Peningkatan pengetahuan ini juga dipengaruhi oleh rasa keingintahuan yang masih tinggi akan hal-hal yang masih asing dan berhubungan langsung dengan mereka yaitu deteksi dini kanker payudara dengan SADARI. Pemilihan dan penggunaan media merupakan salah satu komponen yang mempengaruhi hasil dari promosi Kesehatan yang dilakukan. Hal ini berarti peningkatan pengetahuan wanita usia subur sangat dipengaruhi oleh media yaitu video learning multimedia (VLM). VLM sangat bermanfaat sebagian media pembelajaran untuk berbagai tingkatan usia.

Penelitian ini diperkuat oleh penelitian Hidrah (2008), pemeriksaan payudara sendiri (SADARI) adalah sangat penting sebagai Langkah awal untuk megetahuai apakah menderita kanker 
payudara atau tidak. Adanya informasi tentang SADARI serta kanker payudara menjadi motivasi para wanita untuk menambah pengetahuan tentang area payudara. Hal ini menjadi dasar utama untuk menambah pengetahuan tentang pemeriksaan payudara.

Pada kelompok eksperimen, edukasi diberikan dengan media audio visual yaitu video dan didapatkan hasil peningkatan signifikan setelah diberikan promosi kesehatan. Adanya peningkatan pengetahuan secara signifikan setelah diberikan video, dipengaruhi oleh beberapa faktor seperti media video itu sendiri dan informasi yang terkandung di dalamnya. Media video adalah perpaduan antara audio dan visual yang menyediakan atau menampilkan suatu tindakan, warna dan bunyi yang serasi dan visual-aids (Agustin, 2014). Pemberian informasi dapat dilakukan dengan penyuluhan menggunakan media audio visual (video).

VLM (video learning multimedia) terhadap sikap SADARI

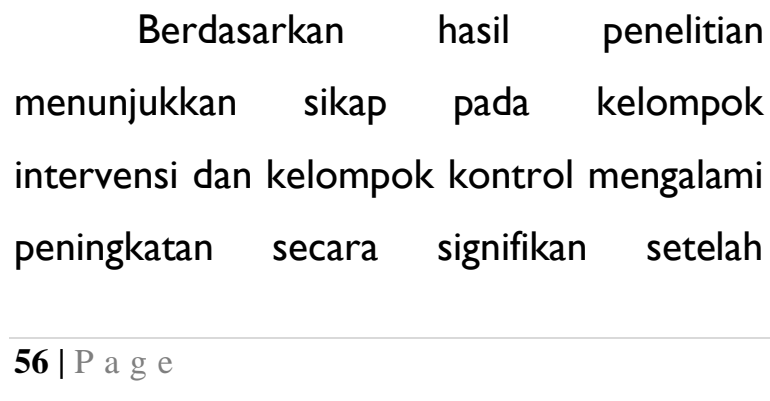

diberikan promosi kesehatan berupa video learning multimedia yang mencerminkan bahwa adanya media video sebagai alat bantu dalam perubahan sikap responden membuktikan bahwa media sangat diperlukan agar sikap responden semakin baik dalam melakukan pemerikasaan payudara sendiri (SADARI). Sikap yang baik dapat disebabkan adanya pengaruh pengetahuan yang meningkat. Peningkatan pengetahuan menjadikan sikap responden juga semakin baik. Terjadinya perubahan sikap yang semakin baik disebabkan sikap dan dipengaruhi oleh pengetahuan, sebagaimana pendapat Wawan (20I0), bahwa pembentukan sikap dipengaruhi oleh pengetahuan.

Dapat dilihat dari hasil penelitian bahwa 30 orang responden kelompok intervensi sebelum perlakuan yaitu sikapnya kurang sebanyak 18 orang dan baik sebanyak 12 orang. Dan setelah dilakukan intervensi sikapnya kurang sebanyak 3 orang dan sikapnya baik sebanyak 27 orang. Setelah dilakukan uji statistik dengan menggunakan uji Paired Sampel Test dengan tingkat kepercayaan 95\%, diperoleh nilai pvalue $=0,000$, artinya terdapat perbedaan sikap sebelum dan sesudah di berikan edukasi terhadap perilaku periksa payudara 
sendiri (SADARI) pada kelompok perlakuan.

Menurut WHO dalam Notoatmodjo (2007), bahwa sikap menggambarkan suka atau tidak suka seseorang terhadap suatu objek. Sikap positif seseorang terhadap nilainilai kesehatan tidak selalu terwujud dalam tindakan nyata. Menurut Notoatmodjo (2003) menyatakan bahwa sikap seseorang akan dipengaruhi oleh kepercayaan, keyakinan, kehidupan emosional, dan kecenderungan untuk berperilaku yang semua itu adalah komponen dari sikap.

Semakin meningkatanya tingkat pengetahuan tentang pemeriksaan payudara sendiri maka akan pempengaruhi sikap para wanita untuk menyadari pentingnya pemeriksaan payudara sendiri untuk mencegah resiko kanker payudara (Manuaba, 2008). Hal tersebut meningkatkan kesadaran pada wanita khususnya usia dewasa awal untuk memotivasi diri sendiri mempraktekkan secara lansung pemeriksaan payudara sendiri sehingga dapat mengetahui kondisi payudaranya.

\section{Simpulan}

Promosi kesehatan berupa video learning multimedia meningkatkan pengetahuan dan sikap pada kelompok intervensi secara signifikan. Hasil ini mencerminkan bahwa adanya media video sebagai alat bantu dalam peningkatan pengetahuan dan perubahan sikap responden membuktikan bahwa media sangat diperlukan agar sikap responden semakin baik dalam melakukan pemerikasaan payudara sendiri (SADARI).

Penelitian ini diharapkan akan berguna bagi wanita di Kelurahan Buakana Kecamatan Rappocini dan masyarakat khususnya perempuan yang lebih berisiko tinggi menderita kanker payudara agar tidak hanya mempelajari tetapi melakukan pemeriksaan payudara sendiri (SADARI) sebagai deteksi dini kanker payudara.

\section{Daftar Pustaka}

Asmadi (2008). Konsep Dasar Keperawatan. Jakarta : EGC.

Brosur Yayasan Kanker Indonesia. (20I2). Deteksi Dini Kanker Payudara. Diakses melalui: http://yayasankankerindonesia.org/ 2012/deteksi-dini-kankerpayudara/. Diakses tanggal 25 November 2015.

Hanifah, A. N. (20I5). Faktor-Faktor Yang Berhubungan Dengan Perilaku Wanita Usia Subur Dalam Melakukan Deteksi Dini Kanker Payudara Metode SADARI Di 
Wilayah Kerja Puskesmas Nusukan Surakarta

Hidayat, A. A. (2009). Metode Penelitian Kebidanan dan Teknis Analisa Data. Jakarta: Salemba Medika.

Kholiq, Ahmad. (20I2). Promosi Kesehatan Dengan Pendekatan Teori Perilaku, Media, Dan Aplikasinya. Jakarta: PT RajaGrafindo Persada.

Munir. (20/3). Multimedia Konsep \& Aplikasi dalam Pendidikan. Bandung: Alfabeta.

Maulana, H. D. J. (2009). Promosi Kesehatan. Jakarta: EGC.

Mulyani, Nina Siti., \& Nuryani. (20/3). Kanker Payudara dan PMS pada
Kehamilan. Yogyakarta: Nuha Medika.

Notoatmodjo S. (2007). Promosi Kesehatan dan Ilmu Perilaku. Jakarta: Rineka Cipta.

Nursalam. (2014). Konsep Penerapan Metode Penelitian IImu Keperawatan. Jakarta: Salemba Medika.

Pamungkas, K. S. (20I5). Hubungan Antara Tingkat Pengetahuan Ibu Tentang Kanker Payudara dengan Perilaku SADARI Pada Kader Posyandu Kecamatan Delanggu. Fakultas Kedokteran Universitas Muhammadiyah Surakarta 